\title{
Post-contrast non-selective double inversion recovery imaging of the coronary arteries in patients with coronary allograft vasculopathy
}

\author{
Sarah A Peel ${ }^{1 *}$, Tarique Hussain ${ }^{1}$, Michael Burch², Matthew Fenton², Andrew Taylor ${ }^{2}$, Vivek Muthurangu ${ }^{2}$, \\ Gerald Greil', René M Botnar ${ }^{1}$
}

From 2011 SCMR/Euro CMR Joint Scientific Sessions Nice, France. 3-6 February 2011

\section{Introduction}

The uptake of gadolinium contrast agent in coronary walls may indicate metabolically-active atherosclerosis (Maintz et al, 2006 ) and therefore be useful in the setting of coronary allograft vasculopathy (CAV). The interpretation of inversion recovery (IR) images can be hampered by signal from tissues with longer T1 times (particularly the myocardium) as tissue suppression is T1 dependent and only optimal for one specific T1 species (e.g. blood). We sought to improve contrastenhanced coronary vessel wall imaging using a novel non-selective double inversion recovery (NS-DIR) prepulse that provides signal suppression over a wide userdefined $\mathrm{T}_{1}$-range.

\section{Methods}

The NS-DIR prepulse with two time delays, $\mathrm{TI}_{1}$ and $\mathrm{TI}_{2}$, was implemented on a $1.5 \mathrm{~T}$ MR scanner. $\mathrm{TI}_{1}$ and $\mathrm{TI}_{2}$ were optimized in MATLAB simulations by minimizing $\mathrm{M}_{\mathrm{Z}}{ }^{\text {NS-DIR }}$ over a user-defined $\mathrm{T}_{1}$-range for a given heart rate.

A $\mathrm{T}_{1}$-phantom containing $11 \mathrm{~T}_{1}$-samples $\left(\mathrm{T}_{1}\right.$-range $=120$ ms-1730ms) was imaged with the IR and NS-DIR pre-pulses for simulated heart rates between 45 and 105bpm. For each prepulse, the signal-to-noise ratio (SNR) was calculated for each sample.

Nine patients who had undergone heart transplantation (ages $=12-17 \mathrm{y}$ ) were imaged $\sim 20$ minutes after injection of $0.2 \mathrm{ml} / \mathrm{kg}$ Gadobutrol using a 32-channel coil on a $1.5 \mathrm{~T}$

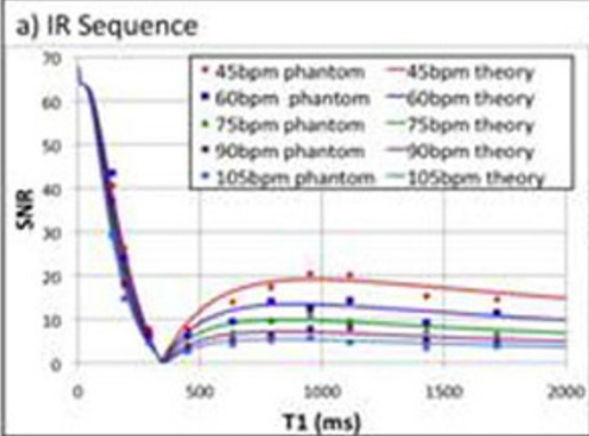

b) NS-DIR Sequence

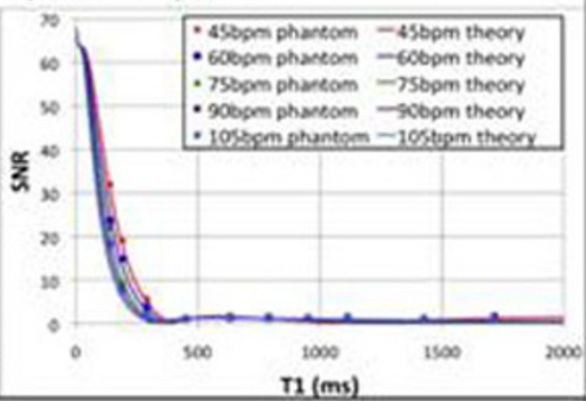

Figure 1 Simulated $M_{2}$ values (solid lines) and phantom SNR values (data points) for a) the IR sequence (T1 set to null T1 species $340 \mathrm{~ms}$ for different heart rates) and $b$ ) the NS-DIR sequence ( $T 1_{1}$ and $T I_{2}$ values optimized to minimize $\mathrm{M}_{2}$ for a range between 200 and $1400 \mathrm{~ms}$ for different heart rates.) N.B. The theoretical $\mathrm{Mz}$ values have been scaled in order to display the data on the same graph.

'Division of Imaging Sciences, King's College London, London, UK

Full list of author information is available at the end of the article

(c) 2011 Peel et al; licensee BioMed Central Ltd. This is an open access article distributed under the terms of the Creative Commons Attribution License (http://creativecommons.org/licenses/by/2.0), which permits unrestricted use, distribution, and reproduction in any medium, provided the original work is properly cited. 


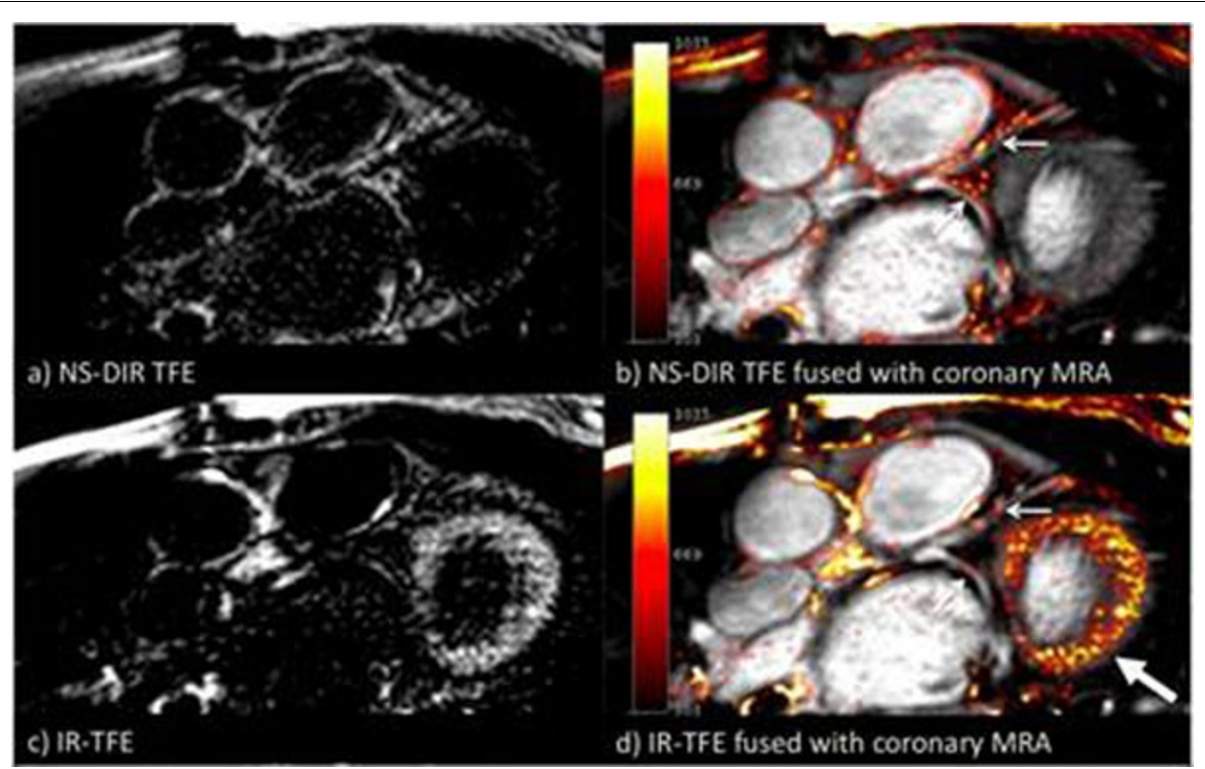

Figure 2 Post contrast imaging of the left coronary artery: a) NS-DIR TFE images, b) NS-DIR TFE images fused with coronary MRA, c) IR-TFE images and d) IR-TFE images fused with coronary MRA. Small arrows indicate enhancement of the coronary vessel walls and the large arrow indicates enhancement in the myocardium in the IR-TFE images.

MR Scanner. Firstly a coronary MRA was performed followed by a targeted, free-breathing, ECG-triggered, 3D-IR segmented gradient-echo (TFE) sequence along the right and left coronary arteries. Imaging parameters included spatial-resolution $=1.25 \times 1.25 \times 3 \mathrm{~mm}, \mathrm{TR} / \mathrm{TE}=3.5 \mathrm{l}$ $1.4 \mathrm{~ms}, \mathrm{FA}=30^{\circ}$ and the TI was chosen to null blood from a Look-Locker sequence. Subsequently, identical planes were repeated with the IR replaced by the NS-DIR prepulse with imaging parameters maintained. Inversion times $\mathrm{TI}_{1}$ and $\mathrm{TI}_{2}$ were set to suppress tissues with $\mathrm{T} 1$ values between $200-1400 \mathrm{~ms}$ according to the patient's heart rate. Imaging was performed every heartbeat at the mid-diastolic rest period.

\section{Results}

Simulations and phantom studies show that the IR sequence (fig.1a) only nulls one $\mathrm{T} 1$ species whereas the NS-DIR sequence (fig.1b) achieves excellent signal suppression over the desired $\mathrm{T}_{1}$-range.

Patient studies showed that the NS-DIR sequence (fig.2a) achieved simultaneous suppression of the blood and myocardium. Only the areas of contrast uptake are visible, which correspond to the path of the LCA (fig.2b). In contrast, interpretation of the IR images (fig.2c and fig.2d) was hampered by the bright signal in the myocardium.

\section{Conclusion}

Simulations and phantom studies demonstrate that the NS-DIR sequence exhibits excellent tissue suppression over a wide $\mathrm{T}_{1}$-range. Preliminary patient data show improvement in contrast agent visualization in the coronary vessel walls in patients with CAV.

\section{Author details}

'Division of Imaging Sciences, King's College London, London, UK. ${ }^{2}$ Great Ormond Street Hospital for Children NHS Trust, London, UK.

Published: 2 February 2011

doi:10.1186/1532-429X-13-S1-P241

Cite this article as: Peel et al:: Post-contrast non-selective double inversion recovery imaging of the coronary arteries in patients with coronary allograft vasculopathy. Journal of Cardiovascular Magnetic Resonance 2011 13(Suppl 1):P241.

\section{Submit your next manuscript to BioMed Central} and take full advantage of:

- Convenient online submission

- Thorough peer review

- No space constraints or color figure charges

- Immediate publication on acceptance

- Inclusion in PubMed, CAS, Scopus and Google Scholar

- Research which is freely available for redistribution 